\title{
Effect of Santolina pectinata (Lag.) Essential Oil to protect against the corrosion of Mild steel in 1.0 M HCl: Experimental and quantum chemical studies
}

\author{
Mounir Manssouri ${ }^{1, *}$, Amal Laghchimi ${ }^{1}$, Abdeslam Ansari ${ }^{1}$, Mohamed Znini ${ }^{1}$, Zouhair \\ Lakbaibi ${ }^{1}$, Yassir El Ouadi ${ }^{2}$ and Lhou Majidi ${ }^{1}$ \\ ${ }^{1}$ Moulay Ismail University of Meknes, Laboratory of Natural Substances \& Synthesis and Molecular Dynamics, \\ Faculty of Sciences and Techniques, P.B 509, 52000, Errachidia, Morocco \\ ${ }^{2}$ Laboratory of Analytical Chemistry, Materials, and Environment (LC2AME), Faculty of Sciences, University \\ of Mohammed Premier, P.B. 717, 60000 Oujda, Morocco
}

\begin{abstract}
The essential oil of Santolina pectinata aerial parts (SP oil) was extracted by hydrodistillation and analyzed by Gas Chromatography (GC) and Gas Chromatography-Mass Spectrometry (GC/MS). 34 components were identified, accounting $59.4 \%$ of the total oil, which (Z)-heptadeca-10,16-dien-7-one (ZHD) was the major component with $28 \%$ of the oil. The protective effect of this oil on the corrosion of mild steel (MS) in $1 \mathrm{M} \mathrm{HCl}$ solution was tested by the measurements of Weight loss (WL), potentiodynamic polarization (PDP), electrochemical impedance spectroscopy (EIS). From WL measurements, the inhibiting effect was raised with the increasing of both concentration inhibitor and temperature. PDP curves led to a mixed-type inhibitor. The charge transfer process mainly controls the results of EIS measurements. The SP oil adsorption not only was discovered to obey Langmuir isotherm but showed a chemical interaction as well. The computational methods such as density functional theory (DFT), Monte Carlo (MC) and radial distribution function (RDF) simulations were also performed to analyze the possible contribution of (Z)-heptadeca-10,16-dien-7-one (ZHD) to the corrosion prevention effect of global oil.
\end{abstract}

Keywords: Santolina pectinata Lag, Essential oil, (Z)-heptadeca-10,16-dien-7-one, Mild steel; Corrosion.

\section{Introduction}

In the broad spectrum of industries, MS tendency to corrosion is caused by aggressive acids such as hydrochloric and sulphuric acids, which are widely used in the pickling processes of metals ${ }^{1,2}$. Therefore, tremendous efforts are being made in order to block or delay the attack of this metal in numerous corrosive media. The use of corrosion inhibitors is viewed as the best way to prevent the corrosion of metal surfaces ${ }^{3}$. Almost all inhibitors of corrosion are synthetic

organic compounds ${ }^{4}$. Owing to the high cost, toxicity, and dangerous effects of synthesized corrosion inhibitor ${ }^{5,6}$, the search for green alternatives that are eco-friendly and non-toxic to protect health and ensure human security is at present attractive ${ }^{7-13}$. In our laboratory, a great deal of research has been carried out to study inhibitive effect using plant extract on the corrosion of steel in acidic media. ${ }^{14-19}$. In this study, our focus is chiefly put on the essential oil of Santolina pectinata (Lag.) (Figure 1).
Santolina pectinata Lag. is, Botanically, a synonym of Santolina rosmarinifolia subsp. pectinata Lag. Maire. It is an endemic herbaceous medicinal, aromatic plant originating from North Mediterranean, mainly found in the Iberian System, North Africa and principally in the eastern Baltic mountains ${ }^{20}$. In Morocco, this species, known locally as "tayrart", is a natural plant which often grows, frequently with Cedrus atlantica and Abie spinsapo, on calcareous substrates in $1500 \mathrm{~m}$ above sea level. On the other hand, it is associated with Quercus ilex and $Q$. canariensis at lower levels ${ }^{21}$. S. pectinata Lag.is an infrequently studied Iberian-Maghreb endemic and, to our knowledge, only one study has investigated the chemical composition of essential oil of this plant collected at Pontones (Jakn) from Spain ${ }^{22}$. The phytochemical analysis and biological characteristics of Santolina species from various origins have also been widely dealt with ${ }^{23}$. Previous studies have shed in evidence the presence of terpenoids, such as germacrane sesquiterpenoids, chrysanthemane monoterpenoids eudesmane, 
flavonoids and coumarins and other secondary metabolites ${ }^{24-27}$.

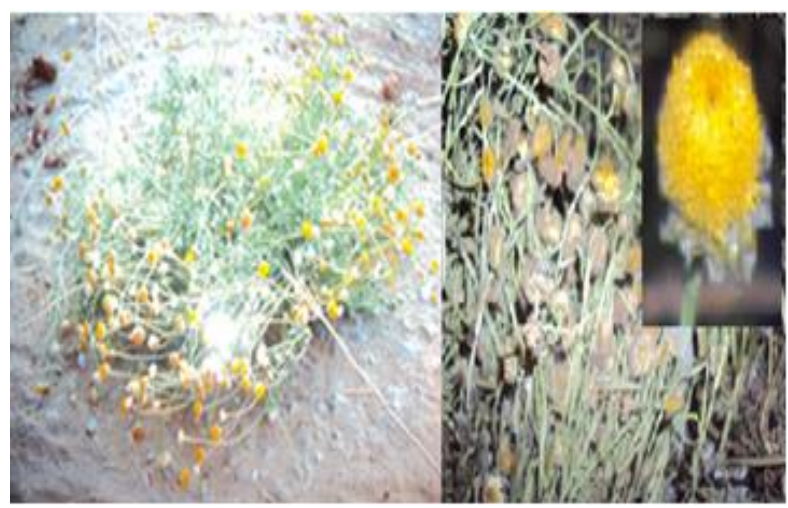

Figure 1. Santolina pectinata (Lag.) in its native habitat in south-eastern of Morocco

Many Santolina species have been used in traditional medicine for a long time $23,28,29$. The main objective of the current research is to study the preventive impact of SP oil as a substance naturally acting on corrosion behavior of MS in $1 \mathrm{M} \mathrm{HCl}$ solution. ZHD is quite likely the major active ingredient which is responsible for the corrosion inhibition of SP oil. To demonstrate that ZHD is really responsible for the anticorrosion effect, this molecule is isolated by fractionation of essential oil using successive column chromatography. After that, a comparative study of SP oil and ZHD alone is carried out. More than that, so as to clarify the interactions between ZHD and the surface of the iron metal, computational calculations based on DFT, Parr functions analysis, MC and RDF simulations were also performed.

\section{Experimental details}

\subsection{Inhibitors}

The experimental phase followed in the current study such as extraction of SP oil, oil fractionation and isolation of ZHD, GC-MS and NMR analysis have been mentioned according to a formerly described experimental procedure in our work ${ }^{30}$. The concentration range of SP oil was $0.25-3 \mathrm{~g} / \mathrm{L}$ in acidic media.

\subsection{Corrosion test}

\subsubsection{Preparation of materials}

MS $(2 \mathrm{~cm} \times 2 \mathrm{~cm})$ coupons containing $0.09 \mathrm{wt} \%(\mathrm{P})$, 0.38 wt.\% (Si), 0.01 wt.\% (Al), 0.05 wt.\% (Mn), 0.21 wt.\% (C), 0.05 wt.\% (S) and the remainder iron (Fe) were used to measure weight loss. The corrosive medium is $1 \mathrm{M} \mathrm{HCl}$ was prepared by dilution of $\mathrm{HCl}$ $(37 \%)$ with distilled water.

\subsubsection{Weight loss measurements}

The specimens of steel were meticulously washed in double-distilled water, dried and then weighed after 6 hours of immersion (100 $\mathrm{ml}$ corrosive solution). Weight loss enabled us to calculate the mean corrosion rate as expressed in $\mathrm{mg} . \mathrm{cm}^{-2} \mathrm{~h}^{-1}$. The corrosion rate (Wcorr) and also the inhibition effectiveness Ew (\%) were calculated based on the Eqs. (1) and (2) respectively:

$$
\begin{aligned}
& \mathrm{W}=\frac{\Delta \mathrm{m}}{\mathrm{S} . \mathrm{t}} \\
& \mathrm{E}_{\mathrm{w}} \%=\frac{\mathrm{W}_{\text {corr }}-\mathrm{W}_{\text {corr(inh) }}}{\mathrm{W}_{\text {corr }}} \times 100
\end{aligned}
$$

where $\Delta \mathrm{m}(\mathrm{mg})$ is the specimen weight before and after immersion in the tested solution, Wcorr and Wcorr(inh) are the values of corrosion weight losses $\left(\mathrm{mg} / \mathrm{cm}^{2} . \mathrm{h}\right)$ of $\mathrm{MS}$ in uninhibited and inhibited solutions, respectively, $\mathrm{S}$ is the area of the mild steel specimen $\left(\mathrm{cm}^{2}\right)$ and $\mathrm{t}$ is the exposure time (h). The degree of surface coverage was calculated using:

$\theta=\frac{\mathrm{W}_{\text {corr }}-\mathrm{W}_{\text {corr(inh) }}}{\mathrm{W}_{\text {corr }}}$

Where $\theta$ is surface coverage; Wcorr (inh) is corrosion rate for steel in the presence of inhibitor, Wcorr is corrosion rate for steel in the absence of inhibitor.

\subsubsection{Electrochemical studies}

Electrochemical measurements were conducted in a conventional three-electrode electrolysis cylindrical Pyrex glass cell. The working electrode (WE) in the form of disc cut from steel has a geometric area of $1 \mathrm{~cm}^{2}$ and is embedded in polytetrafluoroethylene (PTFE). A saturated $\mathrm{Ag} / \mathrm{AgCl}$ electrode and a disc platinum electrode were used respectively as reference (RE) and counter electrodes (CE).

The corrosion inhibition efficiency was derived as given below:

$\mathrm{E}_{\mathrm{i}}(\%)=\left(\frac{\mathrm{I}_{\text {corr }}-\mathrm{I}_{\text {corr,inh }}}{\mathrm{I}_{\mathrm{corr}}}\right) \times 100$

Where $\mathrm{I}_{\text {corr }}, \mathrm{I}_{\text {corr,inh }}$ and represent the corrosion current densities not including and by way of the existence of inhibitor.

Electrochemical impedance spectroscopy measurements were achieved at the open circuit potential for the frequency range of $100 \mathrm{KHz}$ to $10 \mathrm{mHz}$, using a peak-to-peak voltage excitation of $10 \mathrm{mV}$. 
The inhibition efficiency $\mathrm{E}_{\mathrm{Rt}}(\%)$ was calculated from $\mathrm{R}_{\mathrm{t}}$ using the following equation:

$\mathrm{E}_{\mathrm{Rt}}(\%)=\left(\frac{\mathrm{R}_{\mathrm{t}}^{\prime}-\mathrm{R}_{\mathrm{t}}}{\mathrm{R}_{\mathrm{t}}^{\prime}}\right) \times 100$

Where $R_{t}$ and $R_{t}^{\prime}$ are the charge-transfer resistance values without and with inhibitor respectively. $R_{t}$ is the diameter of the loop.

The double-layer capacitance $\left(\mathrm{C}_{\mathrm{dl}}\right)$ and the frequency at which the imaginary component of the impedance is maximal (-Zmax) are found determined by Eq. (6):

$\mathrm{C}_{\mathrm{dl}}=\frac{1}{\omega \cdot \mathrm{R}_{\mathrm{t}}}$

where $\omega=2 \pi . f_{\max }$

Impedance diagrams are obtained for the frequency range $100 \mathrm{KHz}-10 \mathrm{mHz}$ at the open circuit potential for $\mathrm{MS}$ steel in $1 \mathrm{M} \mathrm{HCl}$ in the presence and absence of SP oil.

\subsection{Computational details}

The optimized geometry of the major extract component was performed utilizing DFT method ${ }^{31}$ using program Gaussian $09^{32}$ in the scheme of B3LYP hybrid functional ${ }^{33}$ with the $6-311 \mathrm{G}++(\mathrm{d}, \mathrm{p})$ basis set ${ }^{34}$. Then, the local electrophilic, $\mathrm{P}^{+}$, and nucleophilic, $\mathrm{P}^{-}$, Parr functions ${ }^{35}$ are obtained from the analysis of the Mulliken atomic spin density (ASD) at the radical anion and at the radical cation by adding and removing an electron to the studied inhibitor, respectively. Concerning $\mathrm{MC}$ and RDF simulations ${ }^{36,37}$, the iron surface (111) is built-in Biovia Materials studio $8.0^{38}$ as follows: slab thickness of $45 \AA$, a supercell of $(7 * 7)$ and a vacuum of $30 \AA$ along the ox, oy and oz axis in a simulation box $\mathrm{Fe}(111)$ (i.e., $\mathrm{Lx}=\mathrm{Ly}=\mathrm{Lz}=30 \AA$ ) with periodic boundary conditions to model a representative part of the interface without any arbitrary boundary effects. The build surface of $\mathrm{Fe}$ (111) is optimized using Materials studio $\mathrm{DMol}^{\wedge} 3$ at the $\mathrm{DNP}+$ basis and B3LYP functional. Besides, the complete MC simulation goals to study alignment and adsorption behavior in two environments: at first, in a vacuum (one molecule of ZHD and $\mathrm{Fe}(111)$ surface) and secondly, in solution (one molecule of ZHD, 10 entities of oxonium ions $\left(\mathrm{H}_{3} \mathrm{O}^{+}\right), 15$ molecules of water and $\mathrm{Fe}(111)$ surface) using COMPASS II force field ${ }^{39}$ by means the adsorption locator module integrating in Biovia Materials studio version 8.0. The adsorption behavior was evaluated through RDF analysis using Forcite calculation code ${ }^{40}$. The intense peak happened from $1 \AA$ up to $3.5 \AA$, which is considered a sign of small bond length, which correlates to chemical adsorption. The physical adsorption, on the other hand, is associated with the intense peak that is longer than $3.5 \AA^{41,42}$.

\section{Results and discussion}

\subsection{Essential oil composition}

The use of CC, GC-RI, GC-MS, ESI (+)-MS, 1D and 2D-NMR analyses contributed to the identification of SP oil. Then, 34 components were identified, accounting $59.4 \%$ of the total amount. The SP oil was dominated by oxygenated compounds $(47.9 \%)$ while hydrocarbon compounds didn't exceed $11.5 \%$ of the oil. A non-terpenic oxygenated compound i.e., (Z)heptadeca-10,16-dien-7-one (ZHD) was the major component with $28 \%$ of the oil (Table 1 and Figure 2) ${ }^{30}$.

Table 1. Chemical composition of S. pectinata Lag. aerial parts essential oil.

\begin{tabular}{|c|c|c|c|c|c|}
\hline $\mathbf{N}^{\mathrm{a}}$ & Components ${ }^{b}$ & Ir Lit ${ }^{c}$ & Ir apo ${ }^{d}$ & Ir pol ${ }^{\mathrm{e}}$ & $\%^{\mathrm{f}}$ \\
\hline 1 & Cineole 1,8 & 1024 & 1019 & 1206 & 0.1 \\
\hline 2 & Limonene & 1024 & 1021 & 1199 & 0.2 \\
\hline 3 & (Z)-b-Ocimene & 1029 & 1025 & 1231 & 1.6 \\
\hline 4 & (E)-b-Ocimene & 1041 & 1036 & 1247 & 0.1 \\
\hline 5 & Nonanal & 1076 & 1081 & 1394 & 0.1 \\
\hline 6 & Linalool & 1086 & 1083 & 1544 & 0.2 \\
\hline 7 & Cis Sabinene hydrate & 1083 & 1097 & 1553 & 0.4 \\
\hline 8 & $\beta$-Thujone & 1103 & 1107 & 1422 & 0.4 \\
\hline 9 & Camphor & 1123 & 1121 & 1519 & 0.5 \\
\hline 10 & Lyratol & 1150 & 1138 & 1779 & 0.4 \\
\hline 11 & Borneol & 1150 & 1149 & 1689 & 0.3 \\
\hline 12 & $\alpha$-Terpineol & 1176 & 1172 & 1684 & 0.2 \\
\hline 13 & Estragole & 1175 & 1175 & 1661 & 0.5 \\
\hline 14 & Cuminaldehyde & 1217 & 1212 & 1779 & 0.9 \\
\hline 15 & p-Anisaldehyde $\mathrm{p}$ & 1215 & 1214 & 2028 & 0.6 \\
\hline
\end{tabular}




\begin{tabular}{|c|c|c|c|c|c|}
\hline 16 & Peryllaldehyde & 1248 & 1248 & 1768 & 1.6 \\
\hline 17 & Lyratyl acetate & 1270 & 1257 & 1634 & 0.2 \\
\hline 18 & E-Anethole & 1262 & 1263 & 1813 & 4.1 \\
\hline 19 & Bornyl acetate & 1270 & 1269 & 1573 & 0.8 \\
\hline 20 & Thymol & 1266 & 1272 & 2190 & 0.2 \\
\hline 21 & Undecan-2-one & 1273 & 1276 & 1586 & 0.6 \\
\hline 22 & Carvacrol & 1278 & 1278 & 2214 & 0.6 \\
\hline 23 & $\alpha$-Copaene & 1379 & 1371 & 1489 & 0.6 \\
\hline 24 & Methyleugenol & 1369 & 1374 & 2000 & 0.2 \\
\hline 25 & Isocaryophyllene & 1409 & 1403 & 1570 & 0.2 \\
\hline 26 & E-Caryophyllene & 1421 & 1416 & 1593 & 6 \\
\hline 27 & E- $\beta$-Farnesene & 1446 & 1447 & 1661 & 1.2 \\
\hline 28 & $\alpha$-Curcumene & 1473 & 1470 & 1765 & 0.3 \\
\hline 29 & Germacrene D & 1479 & 1475 & 1701 & 1.3 \\
\hline 30 & Spathulenol & 1572 & 1564 & 2105 & 1.1 \\
\hline 31 & Caryophyllene oxyde & 1578 & 1570 & 1967 & 3.4 \\
\hline 32 & Dillapiole & 1590 & 1591 & 2338 & 1.2 \\
\hline 33 & Tau cadinol & 1633 & 1625 & 2154 & 1.3 \\
\hline 34 & (Z)-heptadeca-10,16-dien-7-one & & 1834 & 2242 & 28 \\
\hline \multicolumn{5}{|c|}{ Total identified } & 59.4 \\
\hline \multicolumn{5}{|c|}{ Hydrocarbon monoterpenes } & 1.9 \\
\hline \multicolumn{5}{|c|}{ Oxygenated monoterpenes } & 6.8 \\
\hline \multicolumn{5}{|c|}{ Hydrocarbon sesquiterpenes } & 9.6 \\
\hline \multicolumn{5}{|c|}{ Oxygenated sesquiterpenes } & 5.8 \\
\hline \multicolumn{5}{|c|}{ Nonterpenic oxygenated compounds } & 28.7 \\
\hline \multicolumn{5}{|c|}{ Others } & 6.6 \\
\hline $\begin{array}{l}\text { a Order o } \\
\text { b Normal } \\
{ }^{\mathrm{c}} \text { Retenti } \\
{ }^{\mathrm{d}} \text { Retenti } \\
{ }^{\mathrm{e}} \text { Retenti } \\
{ }^{\mathrm{f}} \text { Percent }\end{array}$ & $\begin{array}{l}\text { on is given on apolar coloumn (Rtx } \\
\text { t abundances of oil are given on the } \\
\text { ices from the literature on the apola } \\
\text { ices on the Rtx-1 apolar column } \\
\text { ices on the Rtx-wax polar column } \\
\text { mposition is given on the apolar co }\end{array}$ & $\begin{array}{l}\text { r colum } \\
\text { nn }\end{array}$ & & & \\
\hline
\end{tabular}

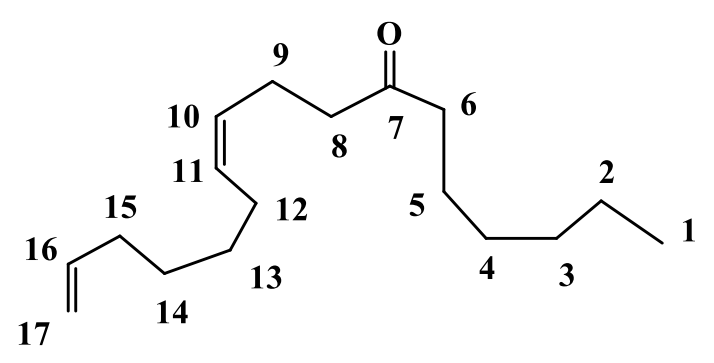

Figure 2. Chemical molecular structure of ZHD

In this paragraph, we determine the WL of the MS sample in corrosive solution with and without 
different concentrations of SP oil at different temperatures $(308-343 \mathrm{~K})$. The values of percentage inhibition efficiency $\mathrm{E}_{\mathrm{w}}(\%)$ and the corrosion rate (W) obtained are summarized in Table 2.

Table 2. Weight loss results for MS in $1 \mathrm{M} \mathrm{HCl}$ with and without different concentrations of aqueous extract at different temperatures.

\begin{tabular}{|c|c|c|c|c|c|c|c|c|c|c|}
\hline \multirow[t]{2}{*}{$\begin{array}{l}C \\
(g / L)\end{array}$} & \multicolumn{2}{|c|}{$308 \mathrm{~K}$} & \multicolumn{2}{|c|}{$313 \mathrm{~K}$} & \multicolumn{2}{|c|}{$323 \mathrm{~K}$} & \multicolumn{2}{|c|}{$333 \mathrm{~K}$} & \multicolumn{2}{|c|}{$343 \mathrm{~K}$} \\
\hline & $\begin{array}{l}\text { W } \\
\left(\mathbf{m g} / \mathrm{cm}^{2} \mathbf{h}\right)\end{array}$ & $\begin{array}{l}\mathbf{E}_{\mathrm{w}} \\
(\%)\end{array}$ & $\begin{array}{c}W \\
\left(\mathbf{m g} / \mathrm{cm}^{2} \mathbf{h}\right)\end{array}$ & $\begin{array}{l}\mathbf{E}_{\mathbf{w}} \\
(\%)\end{array}$ & $\underset{\left(\mathbf{m g} / \mathbf{c m}^{2} \mathbf{h}\right)}{W}$ & $\begin{array}{l}\mathbf{E}_{\mathrm{w}} \\
(\%)\end{array}$ & $\begin{array}{c}W \\
\left(\mathbf{m g} / \mathrm{cm}^{2} \mathbf{h}\right)\end{array}$ & $\mathbf{E}_{\mathrm{w}}(\%)$ & $\begin{array}{c}W \\
\left(\mathbf{m g} / \mathrm{cm}^{2} \mathbf{h}\right)\end{array}$ & $\mathbf{E}_{\mathrm{w}}(\%)$ \\
\hline 0.00 & 0.942 & ...... & 1.751 & $\ldots \ldots$ & 2.836 & $\ldots \ldots$ & 3.641 & $\ldots \ldots$ & 6.301 & $\ldots \ldots$ \\
\hline 0.25 & 0.254 & 73.03 & 0.420 & 76.01 & 0.637 & 77.54 & 0.813 & 77.67 & 1.401 & 77.76 \\
\hline 0.50 & 0.194 & 79.4 & 0.344 & 80.35 & 0.554 & 80.46 & 0.700 & 80.77 & 1.200 & 80.95 \\
\hline 1.00 & 0.150 & 84.07 & 0.245 & 86.00 & 0.369 & 86.98 & 0.441 & 87.88 & 0.687 & 89.09 \\
\hline 2.00 & 0.131 & 86.09 & 0.221 & 87.37 & 0.338 & 88.08 & 0.373 & 89.75 & 0.598 & 90.51 \\
\hline 3.00 & 0.096 & 89.8 & 0.155 & 91.14 & 0.230 & 91.88 & 0.257 & 92.94 & 0.399 & 93.66 \\
\hline
\end{tabular}

The results (Table 2) show that inhibitive efficiency $\mathrm{E}_{\mathrm{w}}(\%)$ goes up considerably with the increase in the concentration of SP oil, indicating that the extent of inhibition depends on the concentration of this inhibitor.

Besides, we notice that these findings demonstrate that the effectiveness of $E_{w}(\%)$ depends on the temperature and increases when it rises from 308 to $343 \mathrm{~K}$. More than that, when the concentration reached to $3 \mathrm{~g} / \mathrm{L}$, the effectiveness $\left(\mathrm{E}_{\mathrm{w}}\right)$ reached a high value of $93.66 \%$ in $1 \mathrm{M} \mathrm{HCl}$ solution at $343 \mathrm{~K}$. This increase can be attributed to the strong adsorption of $\mathrm{SP}$ oil resulting in the formation of a protective layer on the steel surface.

\subsubsection{Polarization tests}

The PDP curves of MS in $1 \mathrm{M} \mathrm{HCl}$ solution without and with a concentration of SP oil at $308 \mathrm{~K}$ are shown in Figure 3. Current density ( $\mathrm{I}_{\mathrm{corr}}$ ), corrosion potential $\left(\mathrm{E}_{\text {corr }}\right)$, cathodic and anodic Tafel slopes $(\beta \mathrm{c}, \beta \mathrm{a})$ are the polarization parameters. These parameters and inhibition efficiency $\left(\mathrm{E}_{\mathrm{i}} \%\right)$ are calculated from the Tafel curves and are summed up in Table 3.

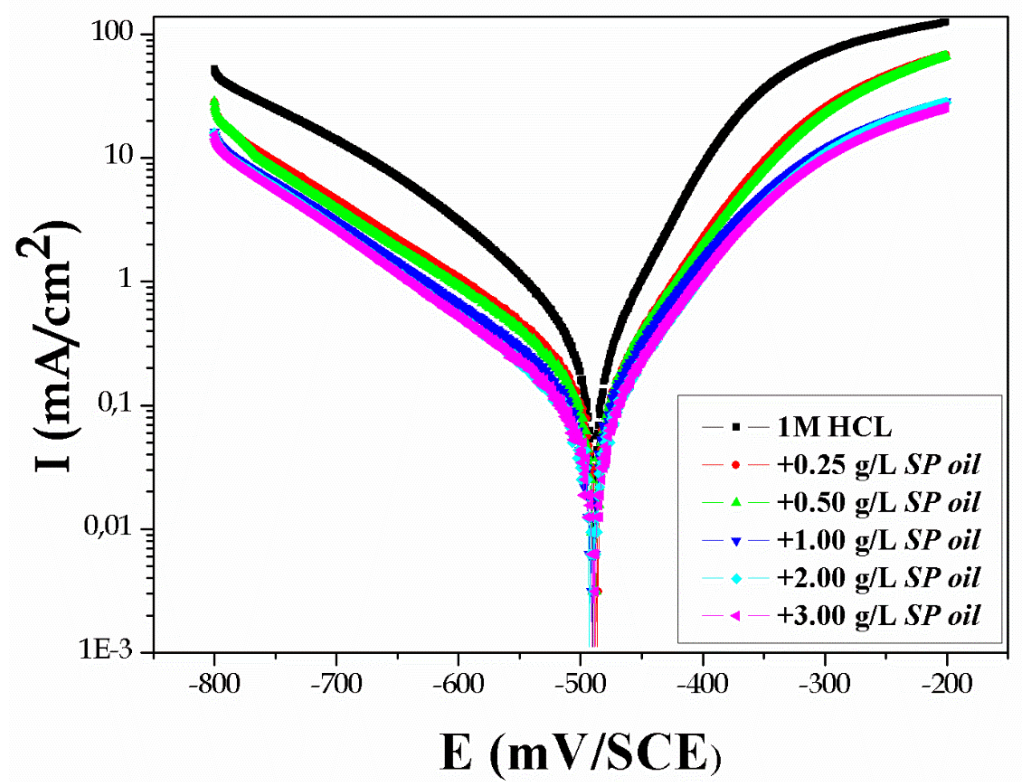

Figure 3. Polarization curves of MS in $1 \mathrm{M} \mathrm{HCL}$ with and without SP oil at various concentrations at $308 \mathrm{~K}$

It is obvious from Figure 3 that the fact of adding SP oil has an inhibitive effect in both the anodic and cathodic parts of the polarization curves. This reveals a modification of the mechanism of cathodic hydrogen evolution and also the anodic dissolution of steel. This, of course, indicates that inhibitor considerably blocks the corrosion process of MS thanks to the adsorption of an organic compound (heteroatom such as oxygen) ${ }^{43}$.

Table 3. Electrochemical parameters for MS in $1 \mathrm{M} \mathrm{HCl}$ containing different concentrations of SP oil at $308 \mathrm{~K}$.

$$
\text { C (g/L) }
$$$$
\text { - Ecorr (mV SCE) }
$$$$
\text { Icorr }\left(\mathrm{mA} \mathrm{cm}^{2}\right)
$$$$
-\beta c(m V)
$$$$
\beta a(m V)
$$$$
\mathrm{E}_{\mathrm{i}} \%
$$ 


\begin{tabular}{|c|c|c|c|c|c|}
\hline $\mathbf{0}$ & 490.1 & 0.5779 & 147.4 & 74.8 & $\ldots \ldots \ldots \ldots$ \\
\hline $\mathbf{0 . 2 5}$ & 480.0 & 0.2214 & 163.0 & 57.0 & 62.00 \\
\hline $\mathbf{0 . 5 0}$ & 480.0 & 0.1840 & 159.2 & 54.0 & 68.16 \\
\hline $\mathbf{1 . 0 0}$ & 490.0 & 0.1243 & 150.6 & 52.1 & 78.50 \\
\hline $\mathbf{2 . 0 0}$ & 490.0 & 0.0907 & 142.6 & 42.0 & 84.50 \\
\hline $\mathbf{3 . 0 0}$ & 480.0 & 0.0865 & 143.2 & 43.1 & $\mathbf{8 5 . 0 3}$ \\
\hline
\end{tabular}

Examination of the data in Table 3 shows that the corrosion current densities ( $\left.\mathrm{I}_{\text {corr }}\right)$ go down significantly with the increase of SP oil concentration. Correspondingly, the inhibition efficiency $\left(\mathrm{E}_{\mathrm{i}} \%\right)$, goes up with the inhibitor concentration to reach its maximum value, $85.03 \%$, at $3 \mathrm{~g} / \mathrm{L}$. This behavior reveals that the SP oil diminishes the corrosion of MS in $\mathrm{HCl}$ solution and behave as a mixed type ${ }^{44}$.

\subsubsection{Electrochemical impedance spectroscopy (EIS)}

Nyquist plots of steel in $1 \mathrm{M} \mathrm{HCl}$ at various concentrations of this oil are given in Figure 4.

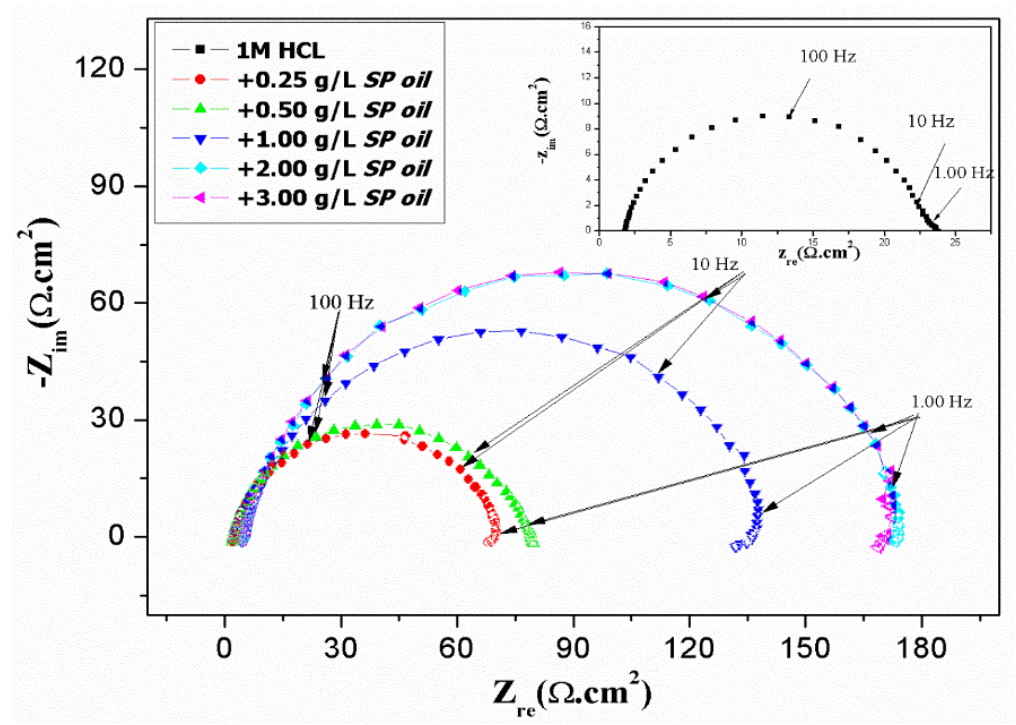

Figure 4. Nyquist plots of MS in $1 \mathrm{M}$ HCL containing various concentrations of SP oil

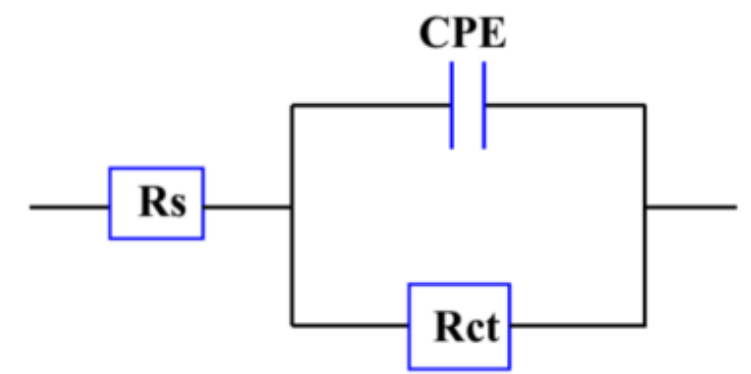

Figure 5. The equivalent circuit used to fit the EIS experiment data

The addition of the SP oil $(0.25-3 \mathrm{~g} / \mathrm{L})$ studied to the corrosive solution leads to an increase in the diameter of the depressed semicircular form. The diameter of Nyquist plots rises with increasing inhibitor concentration. The latter asserts the adsorption of the inhibitor on the metal surface.
Moreover, the impedance spectra present one single capacitive loop, which indicates that the charge transfer takes place at the electrode/solution interface ${ }^{45}$. What is more, is that these capacitive loops are not the perfect semicircles because of a common dispersion effect ${ }^{46}$. that has been attributed to roughness and other inhomogeneities of solid surface $^{47}$.

Table 4. Characteristic parameters evaluated from the impedance diagram for $\mathrm{MS}$ in $1 \mathrm{M} \mathrm{HCl}$ at various concentrations of SP oil. 


\begin{tabular}{|c|c|c|c|c|}
\hline $\mathbf{C}(\mathbf{g} / \mathbf{L})$ & $\mathbf{R}_{\mathbf{c t}}\left(\mathbf{\Omega} \mathbf{~ c m}^{\mathbf{2}}\right)$ & $\mathbf{f}_{\max }\left(\mathbf{H}_{\mathbf{z}}\right)$ & $\mathbf{C d l}\left(\boldsymbol{\mu} \mathbf{F} \mathbf{~ c m}^{\mathbf{2}}\right)$ & $\mathbf{E}_{\mathbf{R t}}{ }^{\text {\% }}$ \\
\hline $\mathbf{0 . 0 0}$ & 21.69 & 100 & 73.37 & $\ldots \ldots \ldots \ldots .$. \\
\hline $\mathbf{0 . 2 5}$ & 067.2 & 50 & 47.35 & 67.73 \\
\hline $\mathbf{0 . 5 0}$ & 078.6 & 50 & 40.51 & 72.39 \\
\hline $\mathbf{1 . 0 0}$ & 126.8 & 31 & 39.67 & 82.98 \\
\hline $\mathbf{2 . 0 0}$ & 166.2 & 31 & 38.30 & 86.95 \\
\hline $\mathbf{3 . 0 0}$ & 169.4 & 31 & 37.58 & $\mathbf{8 7 . 1 9}$ \\
\hline
\end{tabular}

We can conclude from the data obtained about impedance (Table 4) that the $R_{c t}$ values go up as a result of inhibitor concentration and in consequence, the $\mathrm{E}_{\mathrm{Rt}}$ goes up to reach the highest value $87.19 \%$ at $3 \mathrm{~g} / \mathrm{L}$. On the other hand, the decrease in $\mathrm{C}_{\mathrm{dl}}$ is caused by the adsorption of the inhibitor on the metal surface, leading to the formation of film or complex from acidic solution ${ }^{48}$. Addition of SP oil resulted in lower $\mathrm{C}_{\mathrm{dl}}$ values, probably because of the substitute of water molecules by the inhibitor molecules at the electrode surface. The (EIS) results of these capacitive loops are simulated by the equivalent circuit shown in Figure 5 49. In the equivalent circuit, $R_{s}$ is the electrolyte resistance, $R_{c t}$ the charge transfer resistance and $C_{d l}$ is the double layer capacitance ${ }^{50}$.

\subsection{Kinetic/Activation parameters}

The following study consists of calculating activation parameters of the corrosion reaction such as activation energy $\mathrm{E}^{\circ} \mathrm{a}$ activated entropy $\Delta \mathrm{S}^{\circ} \mathrm{a}$ and activation enthalpy $\Delta \mathrm{H}^{\circ} \mathrm{a}$ were calculated using the Arrhenius, and its alternative formulation called transition state Eqs 7 and $8^{50}$.

where $\mathrm{E}^{\circ} \mathrm{a}$ is the apparent activation corrosion energy, $\mathrm{T}$ is the absolute temperature, $\mathrm{R}$ is the universal gas constant, $\mathrm{A}$ is the Arrhenius pre-exponential factor, $\mathrm{h}$ is the Plank's constant. $\mathrm{N}$ is the Avogadro's number, $\Delta \mathrm{S}^{\circ} \mathrm{a}$ is the entropy of activation and $\Delta \mathrm{H}^{\circ} \mathrm{a}$ is the enthalpy of activation.

The activation energies are inferred from the slope $\left(-E^{\circ} \mathrm{a} / \mathrm{R}\right)$ of the logarithm of the corrosion rate $(\mathrm{W})$ versus reciprocal absolute temperature (Figure 6). Their values were reported in Table 5. Using more Eq. (8) plots of $\mathrm{Ln}\left(\mathrm{W} / \mathrm{T}\right.$ ) versus $10^{3} / \mathrm{T}$ (Figure 7) result in straight lines with a slope of $\left(-\Delta \mathrm{H}^{\circ} \mathrm{a} / \mathrm{R}\right)$ and an intercept of $\left(\mathrm{Ln}(\mathrm{R} / \mathrm{Nh})+\left(\Delta \mathrm{S}^{\circ} \mathrm{a} / \mathrm{R}\right)\right)$ from which the values of $\Delta \mathrm{H}^{\circ} \mathrm{a}$ and $\Delta \mathrm{S}^{\circ} \mathrm{a}$ were calculated and are listed in Table 5 .

$$
\begin{aligned}
& \mathrm{W}=\operatorname{Aexp}\left(-\frac{\mathrm{E}_{\mathrm{a}}^{\circ}}{\mathrm{RT}}\right) \\
& \mathrm{W}=\frac{\mathrm{R} \cdot \mathrm{T}}{\mathrm{Nh}} \exp \left(\frac{\Delta \mathrm{S}_{\mathrm{a}}^{\circ}}{\mathrm{R}}\right) \cdot \exp \left(-\frac{\Delta \mathrm{H}^{\circ} \mathrm{a}}{\mathrm{RT}}\right)
\end{aligned}
$$

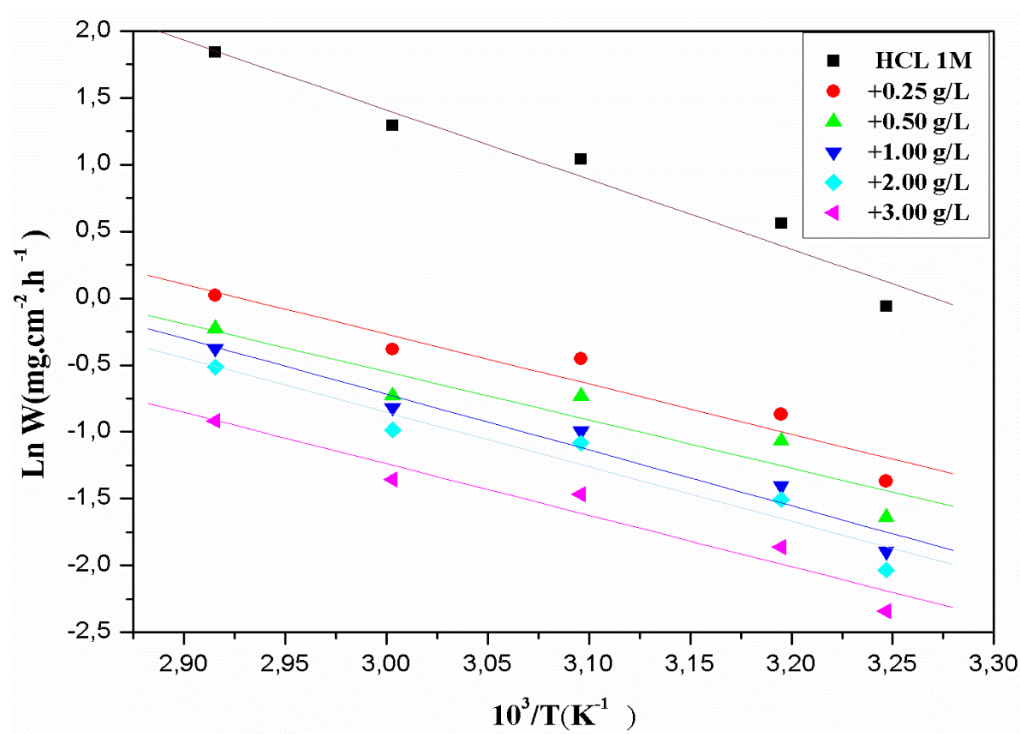

Figure 6. Arrhenius plots for $\mathrm{MS}$ corrosion rates $(\mathrm{W})$ in $1 \mathrm{M} \mathrm{HCl}$ in the absence and presence of different concentrations of SP oil 


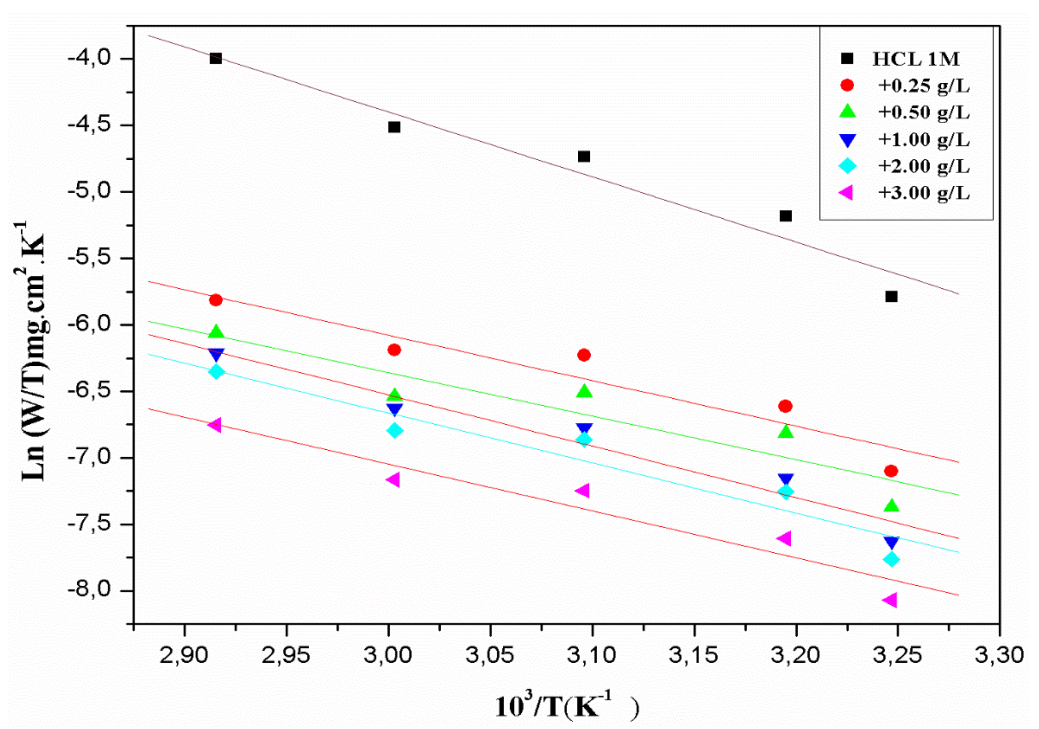

Figure 7. Transition-state plot for $\mathrm{MS}$ corrosion rates (W) in $1 \mathrm{M} \mathrm{HCl}$ in the absence and presence of various concentrations of SP oil

Table 5. Calculated values of kinetic parameters for MS corrosion in $1 \mathrm{M} \mathrm{HCl}$ solution in the absence and presence of various concentrations of SP oil.

\begin{tabular}{|c|c|c|c|c|}
\hline$C(g / L)$ & $\mathbf{E}^{\circ} \mathbf{a}\left(\mathbf{k J} \mathbf{m o l}^{-1}\right)$ & $\Delta \mathbf{H}^{\circ} \mathrm{a}\left(\mathbf{k J} \mathrm{mol}^{-1}\right)$ & 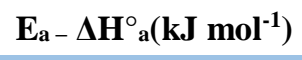 & $\Delta \mathrm{S}_{\mathrm{a}}{ }_{\mathrm{a}}\left(\mathrm{J} \mathrm{mol}^{-1} \mathrm{~K}^{-1}\right)$ \\
\hline HCl 1M & 43.35 & 40.65 & 2.70 & -112.32 \\
\hline 0.25 & 31.14 & 28.44 & 2.70 & -162.93 \\
\hline 0.50 & 29.97 & 27.27 & 2.70 & -168.77 \\
\hline 1.00 & 34.75 & 32.05 & 2.70 & -155.85 \\
\hline 2.00 & 33.91 & 31.21 & 2.70 & -159.47 \\
\hline 3.00 & 32.02 & 29.32 & 2.70 & -168.36 \\
\hline
\end{tabular}

The activation energies in the presence of SP oil are lesser to those in uninhibited acid solution (Table 5). So, the addition of SP oil decreases metal dissolved in $1 \mathrm{M} \mathrm{HCl}$ medium. We note that the increase of $\mathrm{E}_{\mathrm{w}}(\%)$ and the lower value of $\mathrm{E}^{\circ} \mathrm{a}$ are in favor of chemisorption ${ }^{51}$. The positive value of enthalpy of activation $\left(\Delta \mathrm{H}^{\circ} \mathrm{a}\right)$ in the presence of various concentrations of inhibitor shows the endothermic nature of the MS dissolution process, implying that dissolution of steel becomes difficult ${ }^{52}$. However, the negative values of entropy of activation $\left(\Delta \mathrm{S}^{\circ} \mathrm{a}\right)$ indicate that a decrease in disordering takes place continuously from reactants to the activated complex. The activated complex in the rate-determining step represents an association rather than a dissociation step ${ }^{53}$. On the other hand, the average difference value of the $\mathrm{E}^{\circ} \mathrm{a}-\Delta \mathrm{H}^{\circ} \mathrm{a}$ is $2.7 \mathrm{KJ} \mathrm{mol}^{-1}$, which is almost equal to the average value of $\mathrm{RT}$ $\left(2.7 \mathrm{KJ} \mathrm{mol}^{-1}\right)$ at the average temperature $(323 \mathrm{~K})$ of the domain in question. This result agrees that the corrosion process is a unimolecular reaction as described by the known Eq. (9) of perfect gas:

$\mathrm{E}^{\circ} \mathrm{a}-\Delta \mathrm{H}^{\circ} \mathrm{a}=\mathrm{RT}$

\subsection{Adsorption isotherm and thermodynamic parameters}

In this work, we evaluated several types of adsorption isotherm (Frumkin, Temkin and Langmuir). Langmuir was found to give the best description on the adsorption of SP oil. Figure 8 reflects a straight line $\left(\mathrm{R}^{2} \approx 1\right)$ by plotting $\mathrm{C} / \theta$ with regard to the concentration and the corresponding equation. (Eq. (10)) is as follows: Adsorption constant $\left(\mathrm{K}_{\mathrm{ads}}\right)$ value was demonstrated by the intersection of the obtained straight curve and $\mathrm{C} / \theta$ axis (Table 6):

$\frac{\mathrm{C}}{\theta}=\frac{1}{\mathrm{~K}_{\mathrm{ads}}}+\mathrm{C}$

The equilibrium adsorption constant, $\mathrm{K}_{\mathrm{ads}}$ is connected to the standard Gibb's free energy of adsorption $\left(\Delta \mathrm{G}^{\circ}\right.$ ads $)$ with the following equation ${ }^{54}$ :

$\mathrm{K}_{\mathrm{ads}}=\frac{1}{55.5} \exp \left(-\frac{\Delta \mathrm{G}^{\circ} \mathrm{ads}}{\mathrm{RT}}\right)$

where R, T, 55.5 are gas constant, absolute temperature of experiment the molar concentration of water in solution in respectively. 


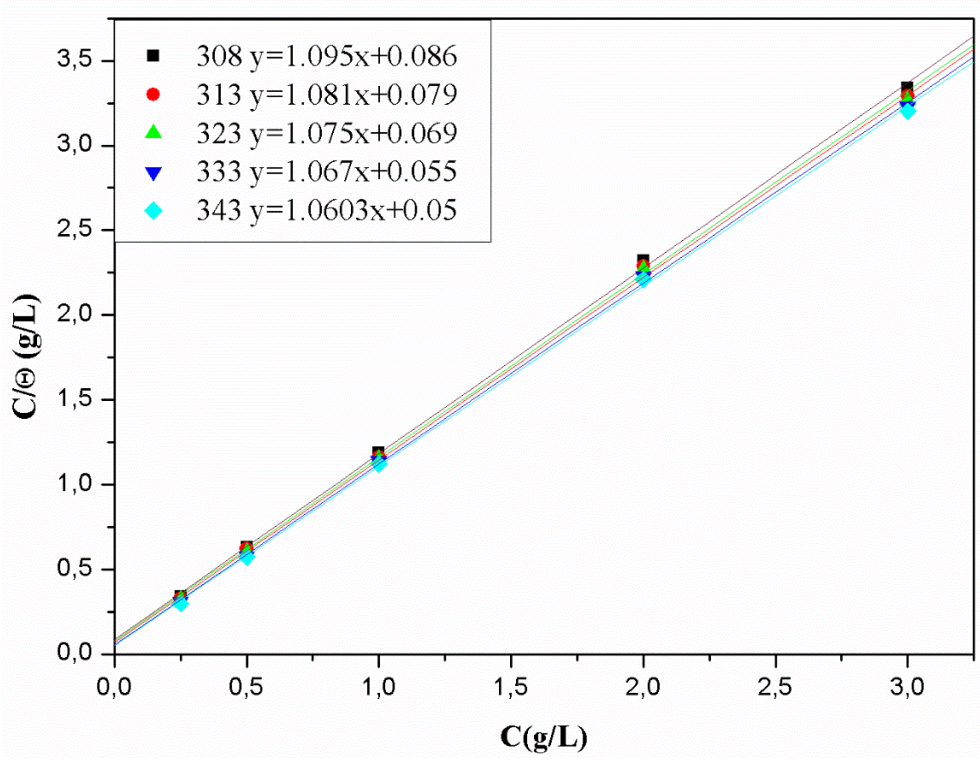

Figure 8. The Langmuir adsorption isotherm of SP oil on the MS surface in $1 \mathrm{M} \mathrm{HCl}$ at different temperatures

Table 6. Thermodynamic parameters for adsorption of SP oil on MS in 1M HCl solution at different temperatures from Langmuir adsorption isotherm.

\begin{tabular}{|c|c|c|c|}
\hline $\mathbf{T}(\mathbf{K})$ & $\mathbf{R}^{\mathbf{2}}$ & $\mathbf{K}_{\text {ads }}\left(\mathbf{L} \mathbf{g}^{-\mathbf{1}}\right)$ & $\mathbf{\Delta G}^{\circ} \mathbf{a d s}\left(\mathbf{k J} \mathbf{~ m o l}^{\mathbf{1}}\right)$ \\
\hline $\mathbf{3 0 8}$ & 0.999 & 11.52 & -23.96 \\
\hline $\mathbf{3 1 3}$ & 0.999 & 12.61 & -24.59 \\
\hline $\mathbf{3 2 3}$ & 0.999 & 14.37 & -25.72 \\
\hline $\mathbf{3 3 3}$ & 0.999 & 18.11 & -27.16 \\
\hline $\mathbf{3 4 3}$ & 0.999 & 20.04 & -28.27 \\
\hline
\end{tabular}

Data in Table 6 revealed that the SP oil was quickly and strongly adsorbed onto the MS surface at a relatively higher temperature. This could be due to the creation of a coordinated bond between the SP oil molecules and the d-orbital of iron ${ }^{55}$. Here, the calculated $\Delta \mathrm{G}^{0}$ ads values are ranging from $-23,96$ to $-28,27 \mathrm{~kJ} \mathrm{~mol}^{-1}$, showing that the adsorption mechanism of SP oil on MS in $1 \mathrm{M} \mathrm{HCl}$ solution at the studied temperatures may be a combination of both electrostatic-adsorption and chemisorption ${ }^{56}$.

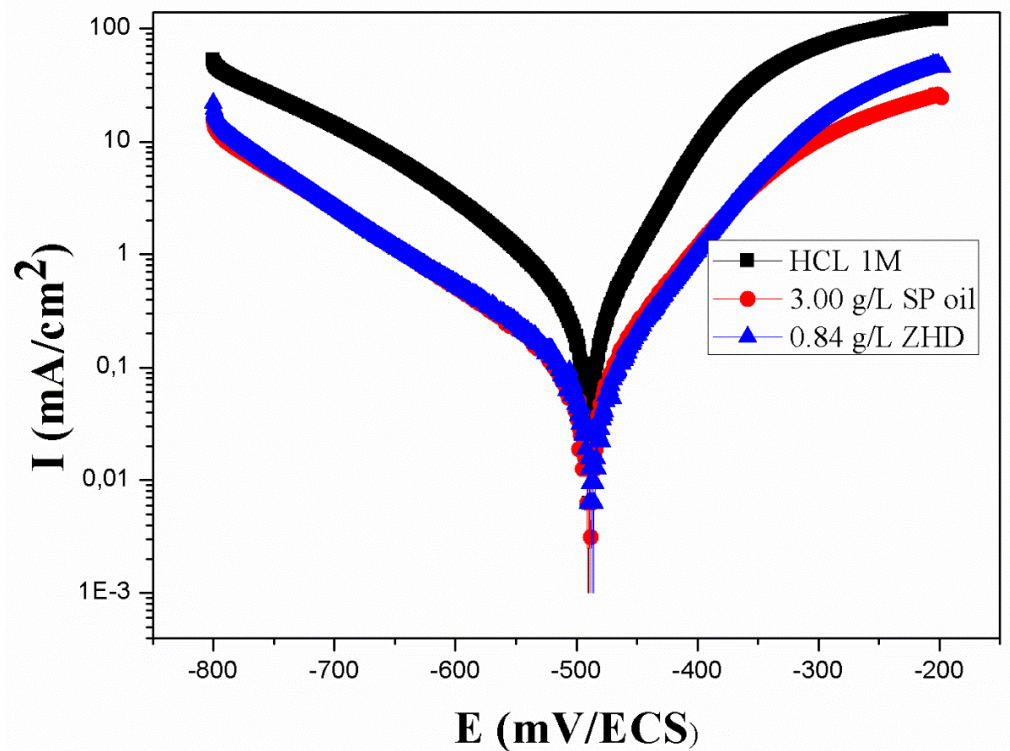

Figure 9. Comparison of polarization curves for MS in $1 \mathrm{M} \mathrm{HCl}$ containing $3 \mathrm{~g} / \mathrm{L}$ of SP oil and $0.84 \mathrm{~g} / \mathrm{L}$ of ZHD 


\subsection{Constituent responsible for inhibition}

The results undoubtedly demonstrated that the inhibitor molecules inhibit the corrosion of the steel surface.

As a consequence, compared together, both SP oil and ZHD are the principal constituents to confirm that this latter is responsible for corrosion inhibition properties of the total oil. In this sense, the ZHD is isolated and evaluated electrochemically by PDP and EIS measurements. Electrochemical test solutions were prepared using a concentration of $3 \mathrm{~g} / \mathrm{L}$ of SP oil and $0.84 \mathrm{~g} / \mathrm{L}(28 \%$ of $3 \mathrm{~g} / \mathrm{L})$ of ZHD molecules. We present in Figure 9 the PDP curves of MS in $1 \mathrm{M} \mathrm{HCl}$ solution with and without a concentration of $3 \mathrm{~g} / \mathrm{L}$ of SP oil and $0.84 \mathrm{~g} / \mathrm{L}$ of ZHD. current density ( $\mathrm{I}_{\text {corr }}$ ), corrosion potential $\left(\mathrm{E}_{\text {corr }}\right)$, cathodic and anodic Tafel slopes $\left(\beta_{\mathrm{c}}, \beta_{\mathrm{a}}\right)$ are the polarization parameters. The parameters and percentage inhibition efficiency $\left(\mathrm{E}_{\mathrm{i}} \%\right)$ are calculated based on the Tafel curves and are given in Table 7.

Table 7. Polarization parameters and the corresponding inhibition efficiency for the corrosion of $\mathrm{MS}$ in $1 \mathrm{M} \mathrm{HCl}$ containing $3 \mathrm{~g} / \mathrm{L}$ of SP oil and $0.84 \mathrm{~g} / \mathrm{L}$ of ZHD at $308 \mathrm{~K}$.

\begin{tabular}{|c|c|c|c|c|c|c|}
\hline & $\mathbf{C}(\mathbf{g} / \mathbf{L})$ & $-\mathbf{E}_{\text {corr }}(\mathbf{m V} \mathbf{S C E})$ & $\mathbf{I}_{\text {corr }}\left(\mathbf{m A} \mathbf{c m}^{2}\right)$ & $\mathbf{- \beta c}(\mathbf{m V})$ & $\boldsymbol{\beta a}(\mathbf{m V})$ & $\mathbf{E}_{\mathbf{i}} \%$ \\
\hline HCl 1M & 0.00 & 490.0 & 0.5779 & 147.4 & 74.8 & $\ldots \ldots \ldots \ldots . .$. \\
\hline SP oil & 3.00 & 480.0 & 0.0865 & 143.2 & 43.1 & $\mathbf{8 5 . 0 3}$ \\
\hline ZHD & 0.84 & 490.0 & 0.0848 & 140.7 & 40.3 & $\mathbf{8 5 . 3 3}$ \\
\hline
\end{tabular}

According to Figure 9, the presence of ZHD causes a prominent decrease of current densities for anodic and cathodic Tafel curves. This decrease indicates the inhibition of anodic metal dissolution and the cathodic hydrogen evolution reaction. This behavior reveals that the ZHD reduces the corrosion of $\mathrm{MS}$ in $\mathrm{HCl}$ medium and acts as a mixed type.

It is crystal clear from the data in Table 7 (attested) that the SP oil and ZHD show a protective efficiency of $85.03 \%$ and $85.33 \%$ at concentration of $3 \mathrm{~g} / \mathrm{L}$ and $0.84 \mathrm{~g} / \mathrm{L}$, respectively. These results indicate that the ZHD molecule can be determined as being the constituent responsible for the inhibitive action of SP oil. The Nyquist plots of steel in $1 \mathrm{M} \mathrm{HCl}$ containing $3 \mathrm{~g} / \mathrm{L}$ of SP oil and $0.84 \mathrm{~g} / \mathrm{L}$ of ZHD are shown in Figure 10. As for the impedance data, they are given in Table 8.

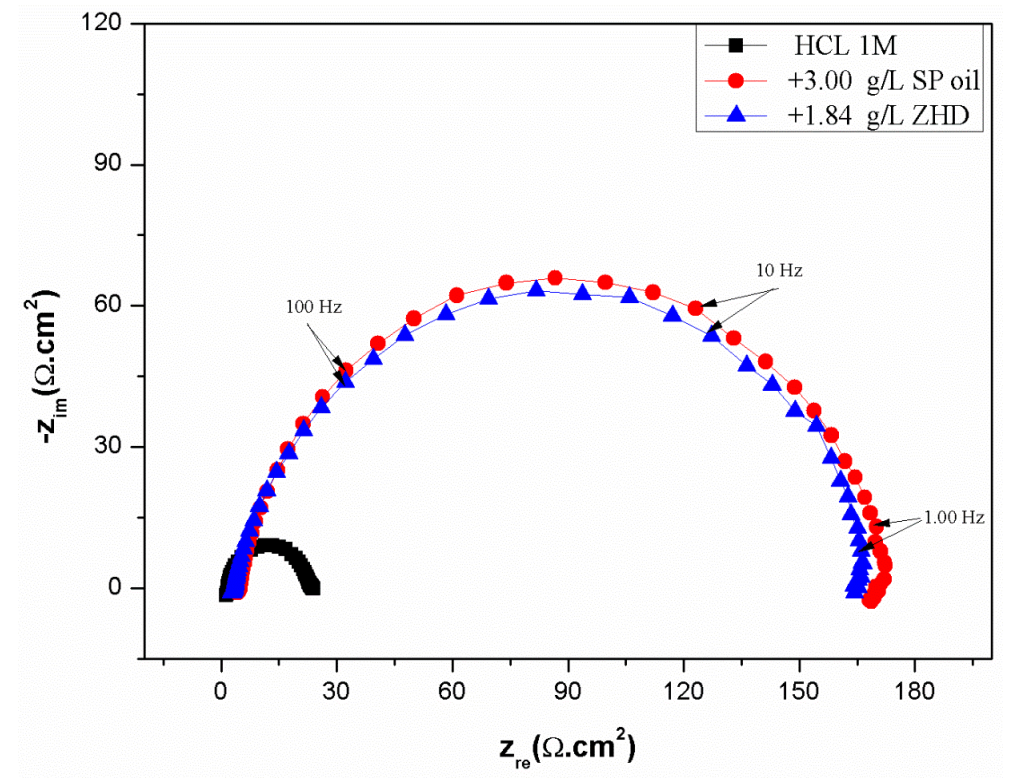

Figure 10. Comparison of Nyquist plots for MS in $1 \mathrm{MHCl}$ containing $3 \mathrm{~g} / \mathrm{L}$ of SP oil and $0.84 \mathrm{~g} / \mathrm{L}$ of ZHD molecules

The impedance spectra present one single capacitive loop, indicating that the charge transfer takes place at the electrode/solution interface and the size of the capacitive loop is similar for the SP oil and the ZHD. The presence of the maximum concentrations of inhibitors augments the value of $R_{t}$ in acidic solution. The impedance data in Table 8 indicates that the $\mathrm{R}_{\mathrm{t}}$ goes up, and the $\mathrm{C}_{\mathrm{dl}}$ goes down because of a decrease in local dielectric constant and/or an increase in the thickness of the electrical double layer. Therefore, the inhibition efficiency $\left(\mathrm{E}_{\mathrm{Rt}}\right)$ increases to 87.19 and $87.81 \%$ at $3 \mathrm{~g} / \mathrm{L}$ for SP oil and $0.84 \mathrm{~g} / \mathrm{L}$ for ZHD, respectively. The inhibition efficiencies provided by ZHD molecule and SP oil are practically similar. These results assert again that the ZHD molecule can be determined as being the component responsible for the inhibitive effect of SP oil. 
Table 8. Characteristic parameters evaluated from the impedance diagram for MS in $1 \mathrm{M} \mathrm{HCl} \mathrm{containing} 3 \mathrm{~g} / \mathrm{L}$ of SP oil and $0.84 \mathrm{~g} / \mathrm{L}$ of $\mathrm{ZHD}$ at $308 \mathrm{~K}$.

\begin{tabular}{|c|c|c|c|c|c|c|}
\hline & $\mathbf{C}(\mathbf{g} / \mathbf{L})$ & $-\mathbf{E}_{\mathbf{c o r r}}(\mathbf{m V} \mathbf{S C E})$ & $\mathbf{R}_{\mathbf{t}}\left(\mathbf{\Omega} \mathbf{~ c m}^{\mathbf{2}}\right)$ & $\mathbf{f} \max (\mathbf{H z})$ & $\mathbf{C}_{\mathbf{d l}}\left(\boldsymbol{\mu} \mathbf{F} \mathbf{~ c m}^{-\mathbf{2}}\right)$ & $\mathbf{E}_{\mathbf{R t}}{ }^{\%}$ \\
\hline HCl 1M & 0.00 & 490.1 & 21.69 & 100 & 73.37 & $\ldots \ldots \ldots \ldots \ldots$ \\
\hline SP oil & 3.00 & 480.0 & 169.4 & 31 & 37.58 & $\mathbf{8 7 . 1 9}$ \\
\hline ZHD & 0.84 & 490.0 & 171.0 & 25 & 37.22 & $\mathbf{8 7 . 3 1}$ \\
\hline
\end{tabular}

3.6. Theoretical study of reactivity and adsorption behaviors

The optimized geometry illustrated in Figure 11 of the inhibitor (Z) -heptadeca-10,16-dien-7-one designed (ZHD) was confirmed by the presence of one and only imaginary frequency in the hessian matrix. The quantum parameters such as the energy of the highest occupied molecular orbital ( $\left.\mathrm{E}_{\mathrm{HOMO}}\right)$, electronic chemical potential, $\mu$, chemical hardness $\eta_{\text {inh }}$, the energy of the lowest unoccupied molecular orbital ( $\left.E_{\text {LUMO }}\right)$, fraction transferred electron between the inhibitor and iron metal, $\Delta \mathrm{N}$, electronegativity, $\boldsymbol{\chi}$ and dipole moment were calculated ${ }^{31}$ (Table 9). These parameters are shown as follows:

$$
\begin{aligned}
& \mu=-\chi=\frac{E_{\text {HOMO }}-E_{\text {LUMO }}}{2} \\
& \eta_{\text {inh }}=E_{\text {LUMO }}-E_{\text {HOMO }} \\
& \Delta N=\frac{\chi_{\mathrm{Fe}}-\chi_{\text {inh }}}{2\left(\eta_{\mathrm{Fe}}+\eta_{\text {inh }}\right)}
\end{aligned}
$$

In this research, we use the theoretical value of $\chi_{\mathrm{Fe}}=7.0 \mathrm{eV}$ and $\eta_{\mathrm{Fe}}=0 \mathrm{eV}$ on the assumption that (for) a metallic bulk ionization potential (I) is equal to an electron affinity (A) as they are softer than the neutral metallic atoms ${ }^{57}$.

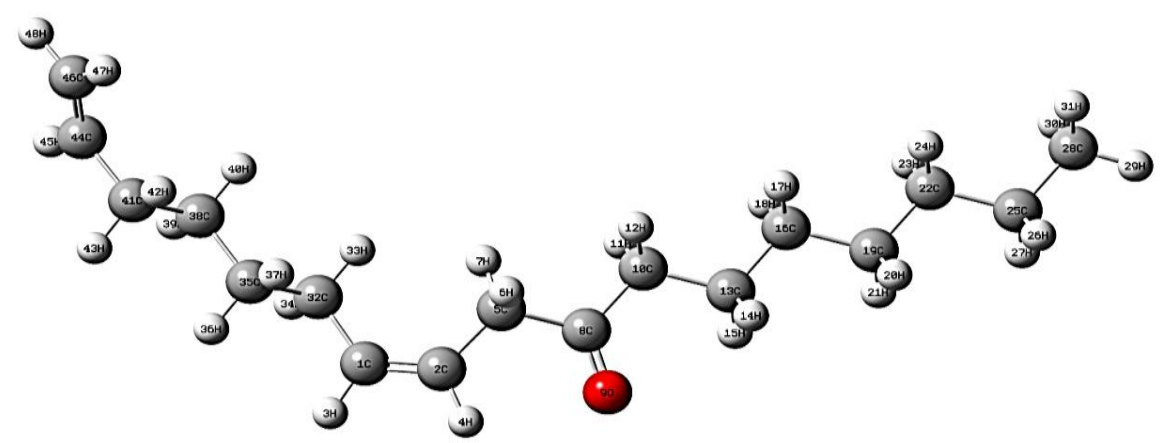

(a)

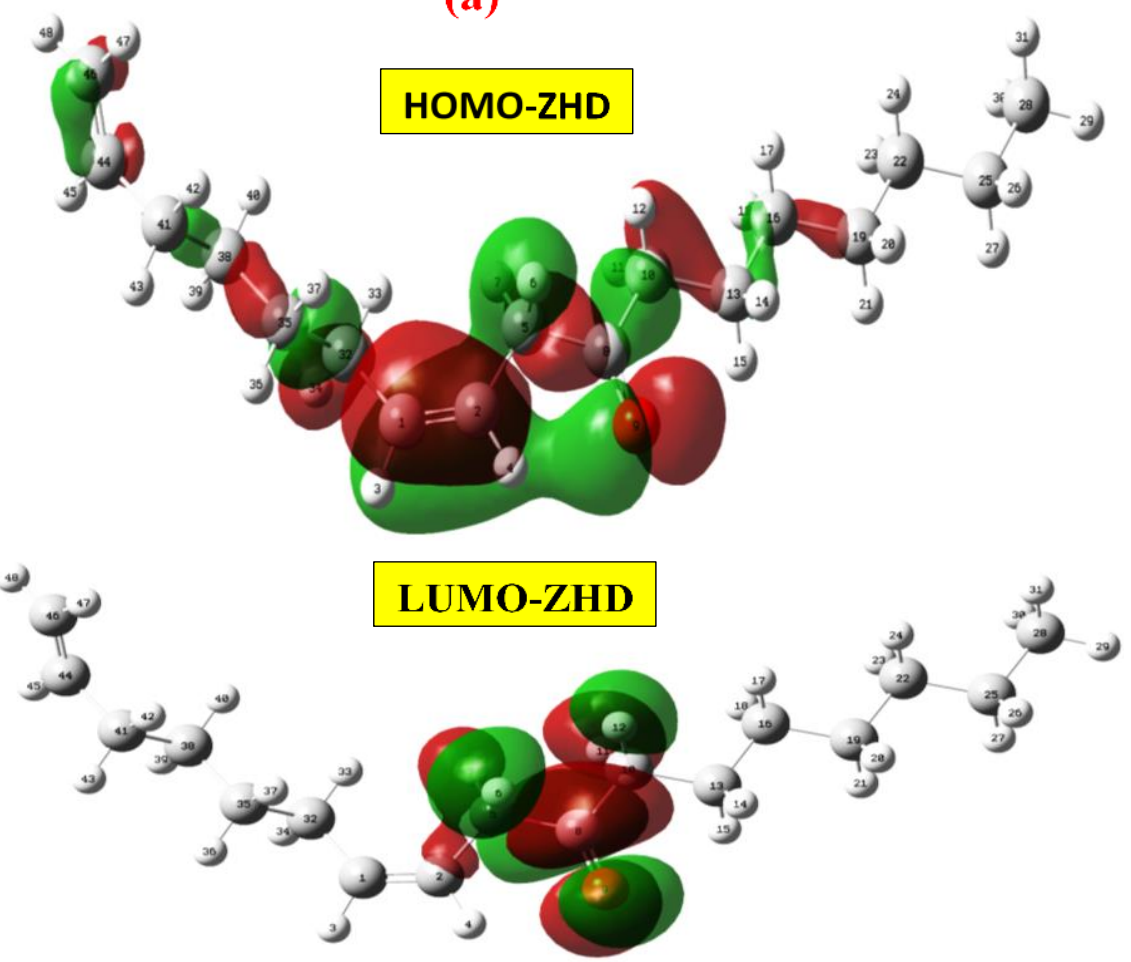

(b)

Figure 11. (a) Optimized structure of ZHD (b) HOMO and LUMO plots of ZHD 
Table 9. Quantum chemical parameters for ZHD. $\mathrm{E}_{\text {HOMO }}$ and $\mathrm{E}_{\mathrm{LUMO}}$ (in eV), electronic chemical potential $\mu$ (in $\mathrm{eV}$ ), chemical hardness $\eta$ (in $\mathrm{eV}$ ), electronegativity $\chi$ (in $\mathrm{eV}$ ), the fraction of transferred electrons $\Delta \mathrm{N}$ and dipole moment (in Debye) calculated using 6-311G++(d,p) in the gas phase.

\begin{tabular}{|c|c|c|c|c|c|c|}
\hline Еномо & ELUMo & $\boldsymbol{\mu}$ & $\boldsymbol{\eta}_{\text {inh }}$ & $\boldsymbol{\chi}$ & $\Delta \mathbf{N}$ & Dipole moment \\
\hline $\mathbf{- 6 . 5 3}$ & -0.46 & -3.04 & 6.07 & 3.04 & 0.33 & 3.33 \\
\hline
\end{tabular}

From Table 9, the electronic chemical potential of ZHD $(-3.04 \mathrm{eV})$ is higher than of iron metal $(-7.00 \mathrm{eV})$. It indicates that the ZHD molecule has the strongest electron-donating ability to the iron metal. This result showed that the inhibitor molecule can give electrons to the empty $3 \mathrm{~d}$ orbital of iron metal, forming a coordinate bond. Therefore, it appears that the fraction transferred electron is positively and less than $3.6(\Delta \mathrm{N}=0.33)$, revealing obviously that inhibition efficiency is only remaining to the electrondonating capability of the inhibitor ${ }^{57}$. Besides, the dipole moment of inhibitor (3.33 Debye) is higher than of water (2.16 Debye) indicating that this inhibitor has superior affinity to interact with metal as compared to the water. It means that the natural compound can adsorb on the MS surface by replacing the adsorbed water molecules.

Nucleophilic and electrophilic sites of the inhibitor structure were examined by the nucleophilic $\mathrm{P}-$ and electrophilic P+ Parr functions, respectively (Table 10). Analysis of the nucleophilic P- Parr of ZHD demonstrates that the reactive atoms (largest values of $\mathrm{P}-$ ) are located over the carbonyl group $\mathrm{C}=\mathrm{O}$ and both ethylenic bond $(\mathrm{C} 1=\mathrm{C} 2$ and $\mathrm{C} 44=\mathrm{C} 46)$. For example, the most reactive ones for $\mathrm{ZHD}$ are oxygen atom $\mathrm{O} 9$ and carbon atoms C1, C2, C44 and C46. Consequently, these centers will interact healthily around the iron surface (110). In other words, the values of electrophilic $\mathrm{P}^{+}$Parr function indicate that the most electrophilic atoms are as follows: C1, H6, C25, C44 and $\mathrm{H} 45$ (highest values of $\mathrm{P}^{+}$). Based on these results, we can deduce that the studied inhibitor which can donate electrons to unoccupied d orbital of the iron surface to form coordinate covalent bonds and can also accept free electrons from the iron surface by using their anti-bonding orbital to form feedback bonds.

Table 10. Nucleophilic $\mathrm{P}-$ and electrophilic $\mathrm{P}+\mathrm{Parr}$ functions of inhibitor ZHD.

\begin{tabular}{|c|c|c|c|}
\hline Atoms & $\mathbf{P}-$ & Atoms & $\mathbf{P +}$ \\
\hline $1 \mathrm{C}$ & 0.174 & $1 \mathrm{C}$ & 0.996 \\
\hline $2 \mathrm{C}$ & 0.136 & $2 \mathrm{C}$ & -0.354 \\
\hline $5 \mathrm{C}$ & 0.026 & $3 \mathrm{H}$ & 0.135 \\
\hline $6 \mathrm{H}$ & 0.021 & $5 \mathrm{C}$ & 0.211 \\
\hline 90 & 0.215 & $6 \mathrm{H}$ & 0.537 \\
\hline $10 \mathrm{C}$ & 0.070 & $12 \mathrm{H}$ & 0.359 \\
\hline $13 \mathrm{C}$ & 0.010 & $17 \mathrm{H}$ & 0.198 \\
\hline $16 \mathrm{C}$ & 0.016 & $18 \mathrm{H}$ & 0.110 \\
\hline $19 \mathrm{C}$ & 0.014 & $25 \mathrm{C}$ & 0.682 \\
\hline $22 \mathrm{C}$ & 0.009 & $26 \mathrm{H}$ & 0.105 \\
\hline $25 \mathrm{C}$ & 0.007 & $29 \mathrm{H}$ & 0.395 \\
\hline $28 \mathrm{C}$ & 0.004 & $30 \mathrm{H}$ & 0.226 \\
\hline $38 \mathrm{C}$ & 0.013 & $31 \mathrm{H}$ & 0.229 \\
\hline $41 \mathrm{C}$ & 0.008 & $33 \mathrm{H}$ & 0.168 \\
\hline $44 C$ & 0.098 & $34 \mathrm{H}$ & 0.201 \\
\hline $46 \mathrm{C}$ & 0.179 & $44 \mathrm{C}$ & 1.166 \\
\hline$* * * *$ & $* * * * *$ & $45 \mathrm{H}$ & 0.542 \\
\hline$* * * *$ & $* * * * *$ & $47 \mathrm{H}$ & 0.231 \\
\hline
\end{tabular}

The most stable configuration of adsorbate/Fe (111) surface system was obtained in both phases vacuum and solution using the adsorption locator module of
MC simulation. In fact, different energies were calculated such as the adsorption energy $\left(E_{a d s}\right)^{42}$, the rigid adsorption energy ( $\left.E_{\text {Rads }}\right){ }^{42}$, the deformation 
energy $\left(E_{\text {Def }}\right)^{42}$ and the compulsory energy to exclude inhibitor from the iron surface $\left(\mathrm{dE}_{\mathrm{ads}} / \mathrm{dNi}\right){ }^{42}$ (Table 11). A bright idea about the most stable adsorption configuration and Radial distribution function RDF (or pair correlation function $\mathrm{g}(\mathrm{r})$ ) in a vacuum and in solution are shown in Figure 12.

Table 11. Adsorption energy $E_{\text {ads }}$, rigid adsorption $E_{\text {Rads }}$, deformation energy $E_{\text {def }}$ and necessary energy to exclude inhibitor from the iron surface $\mathrm{dE}_{\mathrm{ads}} / \mathrm{dNi}$, in $\mathrm{kcal} / \mathrm{mol}$, are given in vacuum and solution.

\begin{tabular}{|c|c|c|c|c|}
\hline & $\mathbf{E}_{\text {ads }}$ & ERads $_{\text {R }}$ & $\mathbf{E}_{\text {Def }}$ & $\begin{array}{c}\text { dEads/dN } \\
\text { (ZHD) }\end{array}$ \\
\hline $\begin{array}{c}\text { Vacuum } \\
\text { ZHD/Fe(111)-surface }\end{array}$ & -42.38 & -176.08 & -38.77 & -42.38 \\
\hline $\begin{array}{c}\text { Solution } \\
\mathrm{ZHD} / \mathbf{1 5 H}_{2} \mathrm{O} / \mathbf{1 0 H}_{\mathbf{3}} \mathrm{O}^{+} \\
/ \mathbf{F e}(\mathbf{1 1 1}) \text {-surface }\end{array}$ & -563.97 & -22.12 & -563.97 & -28.17 \\
\hline
\end{tabular}

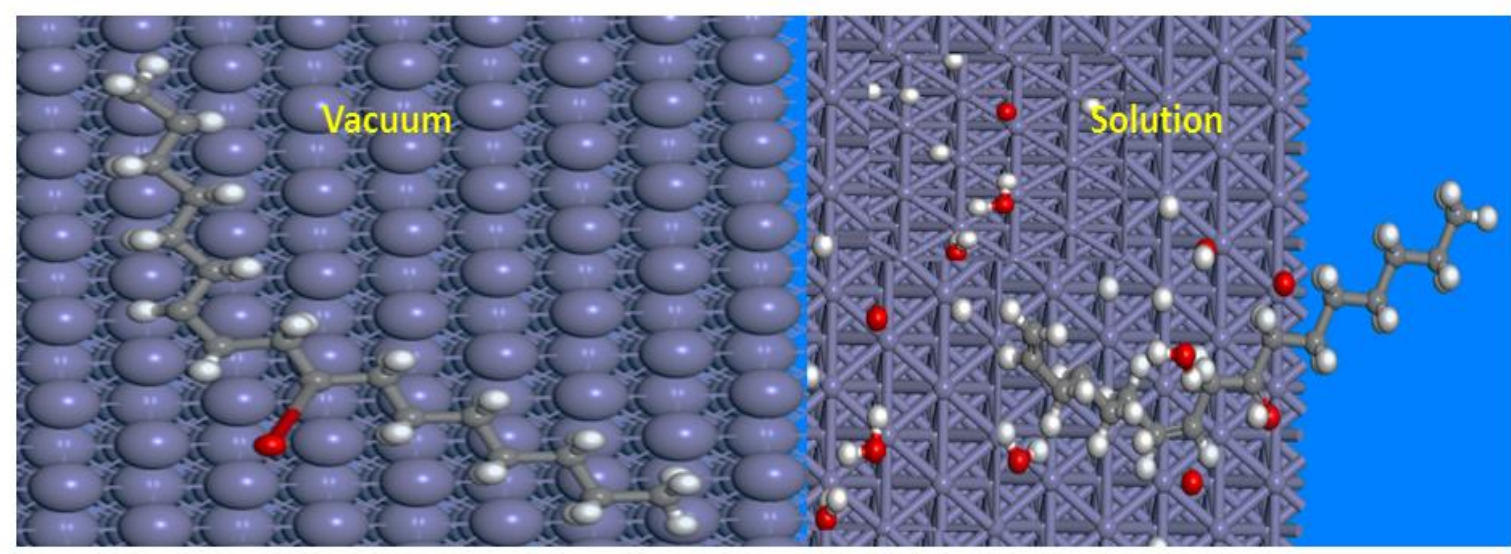

(a)

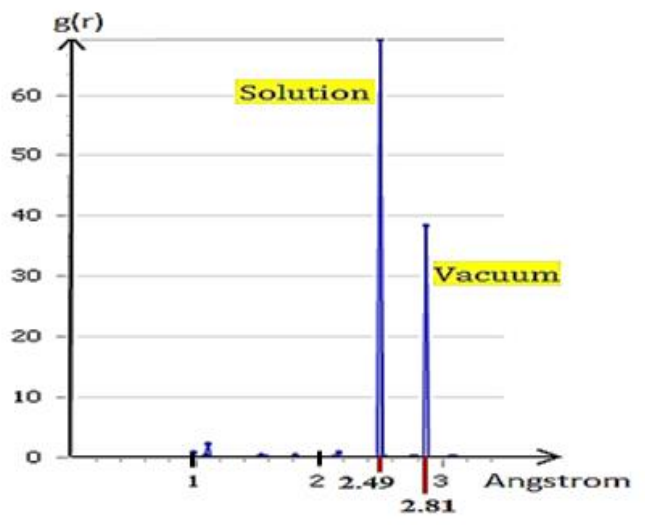

(b)

Figure 12. (a) Top view of the most stable adsorption configuration for the adsorption of the studied molecule on Fe (111). (b) Radial distribution function RDF (g(r)).

The negative values of the adsorption energies for both phases, pointing out that the interaction between inhibitor molecule and $\mathrm{Fe}$ (111) surface is a spontaneous process. Besides, the lower adsorption energy in the solution is a sign of a high inhibition effect in this medium. As such, energy deformation goes down following the order: $\mathrm{E}_{\mathrm{Def}}$ (solution) $<\mathrm{E}_{\mathrm{Def}}$ (vacuum) points to a strong adsorption behavior in the solution than in the vacuum. This result is, to a large extent, consistent with the experiment.

From Figure 12(a), it is made crystal clear that the inhibitor is adsorbed on Fe (111) surface in a parallel form with close contact of $\mathrm{Fe}$ atoms. This can be explained by the strong interaction of the reactive sites of inhibitor with the metal surface as already discussed. Consequently, the inhibitor can be 
adsorbed on the iron surface through not only on the oxygen atom but also over the unsaturated hydrocarbon regions $(\mathrm{C} 1=\mathrm{C} 2$ and $\mathrm{C} 44=\mathrm{C} 46)$. This result presents the similarity with that deduced from nucleophilic $\mathrm{P}-$ Parr function.

Radial distribution function RDF (or pair correlation function $\mathrm{g}(\mathrm{r})$ ) analysis is considered to be of great importance to estimate the bond length and consequently the molecule surface interaction modes (Figure 12 b). As a consequence, the adsorption process of the studied system is the chemisorption type. This is (in) consistent with the present experiment. Also, through this analysis, we noticed that the finding length that is between the iron surface and adsorbent is decreased in case of the solution medium; indicates that the adsorption efficiency would be more in the solution than in the vacuum.

\section{Conclusion}

All in all, The SP oil has proved to be able to inhibit MS corrosion in $1 \mathrm{M} \mathrm{HCl}$ solution efficiently. The charge transfer resistance $\left(\mathrm{R}_{\mathrm{t}}\right)$ increases and the double-layer capacitance $\left(\mathrm{C}_{\mathrm{dl}}\right)$ decreases due to adsorption of the SP oil on the surface of MS. The natural oil acts on MS surface in $1 \mathrm{M} \mathrm{HCl}$ solution as mixed-type inhibitor. The adsorption of the SP oil not only was found to obey Langmuir isotherm but also showed a chemical interaction. We can conclude that the natural substance ZHD from SP oil is responsible for corrosion inhibition and that the Quantum chemical calculations by DFT calculations and Monte Carlo simulation are coherent with the experimental findings.

\section{References}

1- M. G. Hosseini, M. Ehteshamzadeh, T. Shahrabi, Protection of mild steel corrosion with Schiff bases in $0.5 \mathrm{M} \mathrm{H}_{2} \mathrm{SO}_{4}$ solution, Electrochimica Acta, 2007, 52, 3680-3685.

2- E. E. Oguzie, Y. Li, F. H. Wang, Effect of surface nanocrystallization on corrosion and corrosion inhibition of low carbon steel: Synergistic effect of methionine and iodide ion, Electrochimica Acta, 2007, 52, 6988-6996.

3- G. Blustein, J. Rodriguez, R. Romanogli, C. F. Zinola, Inhibition of steel corrosion by calcium benzoate adsorption in nitrate solutions, Corrosion Science, 2005, 47, 369-383.

4- M. Mihit, K. Laarej, H. A. El Makarim, L. Bazzi, R. Salghi, B. Hammouti, Study of the inhibition of the corrosion of copper and zinc in $\mathrm{HNO}_{3}$ solution by electrochemical technique and quantum chemical calculations, Arabian Journal of Chemistry, 2010, 3, 55-60.

5- D. M. Jamil, A. K. Al-Okbi, S. B. Al-Baghdadi, A. A. Al-Amiery, A. Kadhim, T. S. Gaaz, A. A. H. Kadhum, A. B. Mohamad, Experimental and theoretical studies of Schiff bases as corrosion inhibitors, Chemistry Central Journal, 2018, 12, $1-9$.
6- A. Rubaye, A. Abdulwahid, S. B. Al-Baghdadi, A. Al-Amiery, A. Kadhum, A. Mohamad, Cheery sticks plant extract as a green corrosion inhibitor complemented with LC-EIS/MS spectroscopy, International Journal of Electrochemical Science, 2015, 10, 8200-8209.

7- S. Junaedi, A. A. H. Kadhum, A. A. Al-Amiery, A. B. Mohamad, M. S. Takriff, Synthesis and characterization of novel corrosion inhibitor derived from oleic acid: 2-Amino 5-Oleyl-1, 3, 4-Thiadiazol (AOT), International Journal of Electrochemical Science, 2012, 7, 3543-3554.

8- A. Habibiyan, B. Ramezanzadeh, M. Mahdavian, M. Kasaeian, Facile size and chemistrycontrolled synthesis of mussel-inspired biopolymers based on Polydopamine Nanospheres: Application as eco-friendly corrosion inhibitors for mild steel against aqueous acidic solution, Journal of Molecular Liquids, 2020, 298, 111974.

9- A. Dehghani, G. Bahlakeh, B. Ramezanzadeh, M. Ramezanzadeh, Potential role of a novel green eco-friendly inhibitor in corrosion inhibition of mild steel in $\mathrm{HCl}$ solution: Detailed macro/micro-scale experimental and computational explorations, Construction and Building Materials, 2020, 245, 118464.

10-A. Dehghani, G. Bahlakeh, B. Ramezanzadeh, Green Eucalyptus leaf extract: a potent source of bio-active corrosion inhibitors for mild steel, Bioelectrochemistry, 2019, 130, 107339.

11-Z. Sanaei, M. Ramezanzadeh, G. Bahlakeh, B. Ramezanzadeh, Use of Rosa canina fruit extract as a green corrosion inhibitor for mild steel in $1 \mathrm{M} \mathrm{HCl}$ solution: A complementary experimental, molecular dynamics and quantum mechanics investigation, Journal of industrial and engineering chemistry, 2019, 69, 18-31.

12-A. Dehghani, G. Bahlakeh, B. Ramezanzadeh, M. Ramezanzadeh, Detailed macro-/micro-scale exploration of the excellent active corrosion inhibition of a novel environmentally friendly green inhibitor for carbon steel in acidic environments, Journal of the Taiwan Institute of Chemical Engineers, 2019, 100, 239-261.

13-N. Asadi, M. Ramezanzadeh, G. Bahlakeh, B. Ramezanzadeh, Utilizing Lemon Balm extract as an effective green corrosion inhibitor for mild steel in 1M HCl solution: A detailed experimental, molecular dynamics, Monte Carlo and quantum mechanics study, Journal of the Taiwan Institute of Chemical Engineers, 2019, 95, 252-272.

14-M. Znini, J. Paolini, L. Majidi, J.-M. Desjobert, J. Costa, N. Lahhit, A. Bouyanzer, Evaluation of the inhibitive effect of essential oil of Lavandula multifida L., on the corrosion behavior of C38 steel in $0.5 \mathrm{MH} 2 \mathrm{SO} 4$ medium, Research on Chemical Intermediates, 2012, 38, 669-683.

15-M. Manssouri, Y. El Ouadi, M. Znini, J. Costa, A. Bouyanzer, J. M. Desjobert, L. Majidi, Adsorption proprieties and inhibition of mild 
steel corrosion in $\mathrm{HCl}$ solution by the essential oil from fruit of Moroccan Ammodaucus leucotrichus, Journal of Materials and Environmental Science, 2015, 6, 631-646.

16-A. Ansari, M. Znini, A. Laghchimi, J. Costa, P. Ponthiaux, L. Majidi, Chemical composition, adsorption proprieties and corrosion inhibition on mild steel of Mentha rotundifolia L. essential oil from Morocco, Der Pharmacia Lettre, 2015, 7 , 125-140.

17-M. Manssouri, M. Znini, A. Ansari, A. Bouyenzer, Z. Faska, L. Majidi, Odorized and deodorized aqueous extracts of Ammodaucus leucotrichus fruits as green inhibitor for C38 steel in hydrochloric acid solution, Der Pharma Chemica, 2014, 6, 331-345.

18-M. Znini, A. Ansari, J. Costa, O. Senhaji, J. Paolini, L. Majidi, Experimental, Quantum Chemical and Molecular Dynamic Simulations Studies on the Corrosion Inhibition of C38 Steel in $1 \mathrm{M} \mathrm{HCl}$ by Anethum graveolens Essential Oil, Analytical and Bioanalytical Electrochemistry, 2019, 11, 1426-1451.

19-A. Ansari, M. Manssouri, A. Laghchimi, M. Znini, Z. Lakbaibi, M. Azrour, Experimental and theoretical study on corrosion inhibition of new synthesized menthone derivatives (Menthopyrazole compounds) for mild steel in $1 \mathrm{M} \mathrm{HCl}$ solution, Mediterranean Journal of Chemistry, 2020, 10, 62-76.

20-S. López Udías, C. Fabregat, G. Mateo, Santolina ageratifolia" Barnades ex Asso (Compositae) y el agregado S. rosmarinifolia L." Santolina ageratifolia" Barnades ex Asso (Compositae) and their relationships with $\mathrm{S}$. rosmarinifolia L, in: Anales Del Jardín Botánico de Madrid, Real Jardín Botánico, 1997, 55, 285-296.

21-M. Lamrani Alaoui, F. García Novo, Etude comparative de la biodiversite des matorrals des Parcs Naturels de Grazalema (Espagne) et de la Talassemtane (Maroc), Annales de La Recherche Forestiere Au Maroc, 1999, 21-43.

22-M. J. Pérez-Alonso, A. V. Negueruela, The essential oils of four Santolina species, Flavour and Fragrance Journal, 1988, 3, 37-42.

23-R. Tundis, M. R. Loizzo, A Review of the Traditional Uses, Phytochemistry and Biological Activities of the Genus Santolina, Planta Medica, 2008, 84, 627-637.

24-A. F. Barrero, R. Alvarez-Manzaneda, J. F. Quilez, M. M. Herrador, Sesquiterpenes from Santolina chamaecyparissus subsp. squarrosa, Phytochemistry, 1998, 48, 807-813.

25-A. F. Barrero, M. M. Herrador, J. F. Quilez, R. Alvarez-Manzaneda, D. Portal, J. A. Gavin, D. G. Gravalos, M. S. J. Simmonds, W. M. Blaney, Bioactive sesquiterpenes from Santolina rosmarinifolia subsp. Canescens. A conformational analysis of the germacrane ring, Phytochemistry, 1999, 51, 529-541.

26- A. F. Barrero, M. M. Herrador, R. J. ÁlvarezManzaneda, M. Quirós, A. Lara, J. Quílez del
Moral, Longipinene derivatives from Santolina viscosa, Journal of Natural Products, 2000, 63, 587-591.

27-J. A. Marco, J. F. Sanz-cervera, M. Carda, J. Lex, Oxygenated germacranes from Santolina chamaecyparissus, Phytochemistry, 1993, 34,1549-1559.

28-M. Fennane, M. I. Tattou, B. Valdés, Catalogue des plantes vasculaires rares, menacées ou endémiques du Maroc, Herbarium Mediterraneum Panormitanum, 1998.

29-A. F. Barrero, J. F. Sánchez, E. Arana, Germacranolides from Santolina rosmarinifolia subsp. Canescens. Phytochemistry, 1988, 27, 3969-3970.

30-M. Manssouri, A. Ansari, M. Znini, L. Majidi, J. Costa, Chemical Composition of the Santolina pectinata Lag., essential oil from Morocco: Identification of (Z)-heptadeca-10, 16-dien-7-one as a new natural component, Egyptian Journal of Chemistry, 2020, 63, 51-58.

31-R. G. Parr, W. Yang, International series of monographs on chemistry 16: Density-functional theory of atoms and molecules, Oxford University Press, New York, 1989, 142-168.

32-M. J. Frisch et al., GAUSSIAN 09, Revision E. 01, Gaussian Inc., Wallingford CT, 2009.

33-W. J. Hehre, R. Ditchfield, J. A. Pople, Selfconsistent molecular orbital methods. XII. Further extensions of Gaussian-type basis sets for use in molecular orbital studies of organic molecules, Journal of Chemical Physics, 1972, 56, 2257-2261.

34-P. C. Hariharan, J. A. Pople, The influence of polarization functions on molecular orbital hydrogenation energies, Theoretical Chemistry Accounts, 1973, 28, 213-222.

35-L. R. Domingo, P. Pérez, J. A. Sáez, Understanding the local reactivity in polar organic reactions through electrophilic and nucleophilic Parr functions, Royal Society of Chemistry Advances, 2013, 3,1486-1494.

36- O. Dagdag, R. Hsissou, A. Berisha, H. Erramli, O. Hamed, S. Jodeh, A. El Harfi, PolymericBased Epoxy Cured with a Polyaminoamide as an Anticorrosive Coating for Aluminum 2024-T3 Surface: Experimental Studies Supported by Computational Modeling, Journal of Bio- and Tribo-Corrosion, 2019, 5, 58.

37-L. Afia, O. Hamed, M. Larouj, H. Lgaz, S. Jodeh, R. Salghi, Novel natural-based diazepines as effective corrosion inhibitors for carbon steel in $\mathrm{HCl}$ solution: experimental, theoretical and Monte Carlo simulations, Transactions- Indian Institute of Metals, 2017, 70, 2319-2333.

38-Materials Studio version 8.0; Accelrys Software Inc, San Diego, 2016.

39-H. Sun, COMPASS: an ab initio force-field optimized for condensed-phase applications overview with details on alkane and benzene 
compounds, Journal of Physical Chemistry B, 1998, 102, 7338-7364.

40-D. Frenkel, B. Smit, Understanding Molecular Simulation-From Algorithms to Applications, Computational sciences series, Elsevier (Academic Press), 2002, 1, 1-638.

41-Z. Zhang, N. C. Tian, X. D. Huang, W. Shang, L. Wu, Synergistic inhibition of carbon steel corrosion in $0.5 \mathrm{M} \mathrm{HCl}$ solution by indigo carmine and some cationic organic compounds: experimental and theoretical studies, Royal Society of Chemistry Advances, 2016, 6, 22250-22268.

42-S.-W. Xie, Z. Liu, G.-C. Han, W. Li, J. Liu, Z. Chen, Molecular dynamics simulation of inhibition mechanism of 3, 5-dibromo salicylaldehyde Schiff's base, Computational and Theoretical Chemistry, 2015, 1063, 50-62.

43-L. Kadiri, M. Galai, M. Ouakki, Y. Essaadaoui, A. Ouass, M. Cherkaoui, E.-H. Rifi, A. Lebkiri, Coriandrum Sativum. L Seeds Extract as a Novel Green Corrosion Inhibitor for Mild Steel in $1.0 \mathrm{M}$ Hydrochloric and 0.5 M Sulfuric Solutions, Analytical and Bioanalytical Electrochemistry, 2018, 10, 249-268.

44-A. K. Satapathy, G. Gunasekaran, S. C. Sahoo, K. Amit, P. V. Rodrigues, Corrosion inhibition by Justicia gendarussa plant extract in hydrochloric acid solution, Corrosion Science, 2009, 51, 2848-2856.

45- A.R. Sathiya Priya, V.S. Muralidharan, A. Subramania, Development of novel acidizing inhibitors for carbon steel corrosion in $15 \%$ boiling hydrochloric acid, Corrosion, 2008, 64, 541-552.

46-L. Larabi, Y. Harek, M. Traisnel, A. Mansri, Synergistic influence of poly (4-vinylpyridine) and potassium iodide on inhibition of corrosion of mild steel in $1 \mathrm{M} \mathrm{HCl}$, Journal of Applied Electrochemistry, 2004, 34, 833-839.

47-F. Mansfeld, M.W. Kendig, S. Tsai, Synergistic influence of poly (4-vinylpyridine) and potassium iodide on inhibition of corrosion of mild steel in $1 \mathrm{M} \mathrm{HCl}$, Corrosion, 1982, 38, 570.

48-K. Jüttner, Electrochemical impedance spectroscopy (EIS) of corrosion processes on inhomogeneous surfaces, Electrochimica Acta, 1990, 35, 1501-1508.

49-M. Benabdellah, A. Aouniti, A. Dafali, B. Hammouti, M. Benkaddour, A. Yahyi,

A. Ettouhami, Investigation of the inhibitive effect of triphenyltin 2-thiophene carboxylate on corrosion of steel in $2 \mathrm{M} \mathrm{H}_{3} \mathrm{PO}_{4}$ solutions, Applied Surface Science, 2006, 252, 8341-8347. 50-L. Messaadia, O. I. D. El Mouden, A. Anejjar, M. Messali, R. Salghi, O. Benali, O. Cherkaoui, A. Lallam, Adsorption and corrosion inhibition of new synthesized Pyridazinium-Based Ionic Liquid on Carbon steel in $0.5 \mathrm{M} \mathrm{H}_{2} \mathrm{SO}_{4}$, Journal of Materials and Environmental Science, 2015, 6, 598-606.

51-A. M. Badiea, K. N. Mohana, Effect of temperature and fluid velocity on corrosion mechanism of low carbon steel in presence of 2-hydrazino-4, 7-dimethylbenzothiazole in industrial water medium, Corrosion Science, 2015, 51, 2231-2241.

52-E. Khamis, F. Bellucci, R. M. Latanision, E. S. H. El-Ashry, Acid corrosion inhibition of nickel by 2-(triphenosphoranylidene) succinic anhydride, Corrosion, 1991,47, 677-686.

53-F. Bentiss, M. Lebrini, H. Vezin, F. Chai, M. Traisnel, M. Lagrené, Enhanced corrosion resistance of carbon steel in normal sulfuric acid medium by some macrocyclic polyether compounds containing a 1, 3, 4-thiadiazole moiety: AC impedance and computational studies, Corrosion Science, 2009, 51, 2165-2173.

54-H. Ouici, M. Tourabi, O. Benali, C. Selles, C. Jama, A. Zarrouk, F. Bentiss, Adsorption and corrosion inhibition properties of 5-amino 1, 3, 4-thiadiazole-2-thiol on the mild steel in hydrochloric acid medium: Thermodynamic, surface and electrochemical studies, Journal of Electroanalytical Chemistry, 2017, 803,125-134. 55-M. A. Hegazy, A. S. El-Tabei, A. H. Bedair, M. A. Sadeq, An investigation of three novel nonionic surfactants as corrosion inhibitor for carbon steel in $0.5 \mathrm{M} \mathrm{H}_{2} \mathrm{SO}_{4}$, Corrosion Science, 2012, 54, 219-230.

56-E. Kowsari, M. Payami, R. Amini, B. Ramezanzadeh, M. Javanbakht, Task-specific ionic liquid as a new green inhibitor of mild steel corrosion, Applied Surface Science, 2014, 289, 478-486.

57-M. J. C. Dewar, W. Thiel, Ground states of molecules. 38. The MNDO method. Approximations and parameters, Journal of the American Chemical Society, 1977, 99, 4899-4907. 